6 - ORIGINAL ARTICLE

ISCHEMIA-REPERFUSION

\title{
Grape seed protects cholestatic rats liver from ischemia/reperfusion injury ${ }^{1}$
}

\author{
Tuğrul Çakır', Arif AslanerI, Seçkin Özgür Tekeli ${ }^{I I}$, Kasım Güneş ${ }^{\mathrm{III}}$, Erdem Kinaci ${ }^{\mathrm{IV}}$, Uğur Doğanv ${ }^{\mathrm{v}}$ Feyza Tekeli ${ }^{\mathrm{VI}}$, Cebrail
} Akyüz ${ }^{\mathrm{VII}}$, Süleyman Koç ${ }^{\mathrm{VIII}}$, Necat Yılmaz ${ }^{\mathrm{IX}}$

DOI: http://dx.doi.org/10.1590/S0102-865020160030000006

${ }^{\mathrm{I}} \mathrm{MD}$, Chief Asssitant, Department of General Surgery, Antalya Training and Research Hospital, Antalya, Turkey. Conception, design, intellectual and scientific content of the study.

${ }^{I I M D, ~ C h i e f ~ A s s i t a n t, ~ D e p a r t m e n t ~ o f ~ B i o c h e m i s t r y, ~ A n t a l y a ~ T r a i n i n g ~ a n d ~ R e s e a r c h ~ H o s p i t a l, ~ A n t a l y a, ~ T u r k e y . ~ I n t e r p r e t a t i o n ~ o f ~ d a t a . ~}$

IIIMD, Assistant Professor, Department of Histology and Embryology, Sakarya University, Faculty of Medicine, Sakarya, Turkey Interpretation of data.

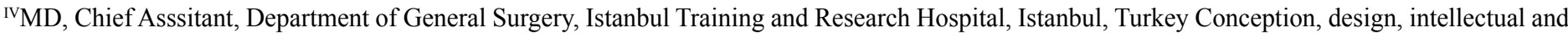
scientific content of the study.

${ }^{\mathrm{v}} \mathrm{MD}$, Chief Asssitant, Department of General Surgery, Antalya Training and Research Hospital, Antalya, Turkey. Conception, design, intellectual and scientific content of the study. ${ }^{\mathrm{VI}}$

Department of Biochemistry, Antalya Training and Research Hospital, Antalya, Turkey. Interpretation of data.

${ }^{\mathrm{VII} M D}$, Department of Gastroenterology, Haydarpaşa Training and Research Hospital, Istanbul, Turkey. Interpretation of data.

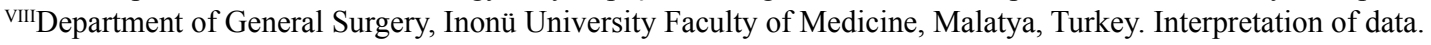

${ }^{\mathrm{Ix}} \mathrm{MD}$, Assistant Professor, Department of Biochemistry, Antalya Training and Research Hospital, Antalya, Turkey. Scientific content of the study, critical revision.

\section{ABSTRACT}

PURPOSE: To determine the effect of grape-seed extract against ischemia/reperfusion injury in cholestatic liver.

METHODS: Eighteen Wistar albino rats were divided into three groups. In control and study groups, cholestasis was provided by bile duct ligation. Seven days later, the rats were subjected to $30 \mathrm{~min}$ hepatic ischemia, followed by 60 min of reperfusion. Oral administration of $50 \mathrm{mg} / \mathrm{kg} /$ day grape-seed extract was started 15 days before bile duct ligation and continued to the second operation in the study group. Serum, plasma and liver samples were taken. Laboratory analysis, tissue gluthation, malondialdehyde, myeloperoxidase levels and histopathological examination were performed.

RESULTS: Significant decrease in liver gluthation level and significant increase in malondialdehyde level and myeloperoxidase activity were observed after ischemia/reperfusion in cholestatic rats. Serum and plasma levels for laboratory analysis were also significantly higher in cholestatic I/R group. Hepatic necrosis and fibrosis were detected in histopathological examination. Oral grape-seed extract administiration reversed all these parameters and histopathological findings except serum bilirubin levels.

CONCLUSION: Oral grape-seed extract treatment can improve liver functions and attenuate the inflammation and oxidative stress in cholestatic ischemia/reperfusion injury.

Key words: Grape Seed Extract. Ischemia. Injury. Liver. Reperfusion. Rats. 


\section{Introduction}

Hepatic ischemia and reperfusion (I/R) injury is a common problem after liver transplantation and major hepatectomies. After an ischemic period, reperfusion of the hepatocytes causes the release of toxic reactive oxygen species (ROS) that induce lipid peroxidation, mitochondrial damage, and apoptosis ${ }^{1}$. Although many compounds with antioxidant properties have been studied on experimental I/R injury models to decrease the harmful effects of $R^{2}{ }^{2}$, there is still no reliable drug in clinical use for this purpose.

In the presence of cholestasis, the liver is more susceptible to reperfusion injury ${ }^{3,4}$. When the biliary flow comes to a standstill, a rapid injury to sinusoidal endothelial cells, accumulation of neutrophils, and activation of Kuppfer cells are induced ${ }^{4}$. The activated neutrophils and Kuppfer cells are the source of ROS and oxidative damage $e^{5,6}$. In real life, cholestasis is a common finding in hepatic or biliary pathologies requiring major hepatic surgery; therefore, cholestatic I/R injury models are more valuable for reflecting these clinical conditions.

The antioxidant features of grape-seed extract (GSE) have been known for a long time ${ }^{7}$. Procyanidines (or Proanthocyanidines), a class of derivatives of Flavan-3-ols that is the major biochemically active component of GSE, has powerful free radical scavenging capacity ${ }^{7,8}$. Hence, the success of GSE treatment against oxidative stress injury was previously demonstrated in $\mathrm{I} / \mathrm{R}$ injury ${ }^{9}$ and obstructive jaundice ${ }^{10}$ models separately. In this study, a combined experimental model, cholestatic I/R injury model, was used to put forth the effect of oral GSE treatment in cholestatic rats that underwent I/R injury.

\section{Methods}

Experimental procedures of this study were reviewed and approved by Akdeniz University, Local Committee of Animal Research and Ethics (decision number: 2014.09.16). The animals were obtained from the Laboratory of Experimental Animals of Akdeniz University. The number of animals was determined after power analysis. Eighteen Wistar Albino male rats (weighing 250$300 \mathrm{~g} ; 5-7$ months of age) were used in this study. The rats were kept at a $22^{\circ} \mathrm{C}$ constant temperature with a 12 -h light/dark cycle and humidity at $60 \%$ and food and water available ad libitum. They were kept in plastic based production cages with plastic sides that were covered by wire knitted covers placed over the top of the cages.

\section{Experimental design and study groups}

The rats were divided into three groups. In the sham group, an abdominal incision was closed without any other surgical manipulation after laparatomy in both operation days. In the cholestatic I/R injury group, I/R injury and cholestasis model were performed without any special treatment. In the $I / R$ injury plus GSE treated (I/R+GSE) group, in addition to the $\mathrm{I} / \mathrm{R}$ injury and cholestasis model, oral GSE treatment was administered. GSE in this study is an extract from Vitis vinifera (Mikro-Gen Pharmaceuticals, Istanbul, Turkey) and contains proanthocyanidins (oligomers of monomeric polyphenols; not less $70 \%$ polyphenolic compound).

In the study group, GSE was dissolved in water and administered to $\mathrm{I} / \mathrm{R}+\mathrm{GSE}$ group for 15 days prior to first operation and repeated for more 7 days during cholestasis period at a daily dose of $50 \mathrm{mg} / \mathrm{kg}$, orally. The sham and cholestatic I/R groups received equal amounts of saline for 21 days. None of the animals died during these procedures.

\section{Surgical procedures}

Fist operation day: After 6 hours of fasting, anesthesia was provided by intraperioneal injection of $75 \mathrm{mg} / \mathrm{kg}$ ketamin HCL (Ketasol ${ }^{\circledR}$, Richterpharma Ag, Wels Austria) and xylazin hydrochloride (Rompun, Bayer, Istanbul, Turkey). Antisepsis of incisional area was provided by application of povidone-iodine. Then a midline laparotomy was performed using 15-no surgical scalpel. In the sham group, the abdomen was closed in a running single layer with 3-0 silk suture. In the other two groups, the common bile duct was isolated, and ligated with 4-0 silk suture. Then, the abdomen was closed in the same manner. After the smooth ending of anesthesia, the rats had free access to food and water. The rats received postoperative analgesia with acetaminophen (Paracetamol; Sigma-Aldrich Chemistry, Steinheim, Germany) in a dose of $50 \mathrm{mg} / \mathrm{kg} / \mathrm{d}$ by oral gavage.

Second operation day: One week later, the same midline incision was opened in all the groups. In the sham group, the incision was closed without any manipulation. In the other two groups, the partial liver ischemia was performed with an atraumatic clamp by occluding the portal vein and hepatic artery for 30 minutes. Later, the liver was reperfused with blood for 60 minutes by the release of the clamp. After that, the rats were sacrificed by decapitation, and the blood and liver tissue samples were obtained immediately. 


\section{Laboratory examinations}

Blood was drawn from the abdominal aorta and centrifuged at $3.000 \mathrm{~g}$ for $10 \mathrm{~min}$. Serum was collected and stored at $-20^{\circ} \mathrm{C}$. Serum levels of total bilirubin (Tbil), direct bilirubin (Dbil), alanine aminotransferase (ALT), aspartate aminotransferase (AST), lactate dehydrogenase (LDH), and alkaline phosphatase (ALP) were measured with an auto biochemical analyzer (Hitachi, Japan).

Tissue samples were taken from the right lobe of the liver, washed in cold saline, quickly put into $-196{ }^{\circ} \mathrm{C}$ liquid nitrogen during sampling, and then kept at $-80^{\circ} \mathrm{C}$ until use. Before detection, samples were first thawed in $4^{\circ} \mathrm{C}$ condition and subsequently homogenized in ice-cold phosphate buffer ( $\mathrm{pH} 7.4)$.

Plasma TNF- $\alpha$ and IL- $1 \beta$ were analyzed using enzyme-linked immunosorbent assay (ELISA) kits (Biosource International, Nivelles, Belgium) in accordance with the manufacturer's instructions and guidelines. These assay kits were particularly selected because of their high degree of sensitivity, specificity and inter-assay and intra-assay precision, and because they require a small amount of plasma sample.

To determine Malondialdehyde (MDA) and Gluthatione (GSH) levels, hepatic tissue samples were homogenized in icecold $150 \mathrm{~mm}$ KCL. The MDA levels were assayed for the products of lipid peroxidation ${ }^{11}$. Results were expressed as nmol MDA/g tissue. GSH levels were measured by spectrophotometric method using Ellman's reagent ${ }^{12}$. Results were expressed as nmol GSH/g tissue. Serum MDA and GSH levels were measured using the same method.

Tissue-associated myeloperoxidase (MPO) activity was measured according to the procedure reported by Hillegas et al. ${ }^{13}$. Hepatic tissue samples were homogenized in $50 \mathrm{~mm}$ potassium phosphate buffer ( $\mathrm{PB}, \mathrm{pH}$ 6.0) and homogenates were centrifuged at $41400 \mathrm{~g}$ for $10 \mathrm{~min}$; pellets were suspended in $50 \mathrm{~mm} \mathrm{~PB}$ containing $0.5 \%$ hexadecyltrimethylammonium bromide. After three cycles of freezing and thawing, with sonication between the cycles, the samples were centrifuged at $41400 \mathrm{~g}$ for $10 \mathrm{~min}$. Volumes of $0.3 \mathrm{ml}$ were added to $2.3 \mathrm{ml}$ of reaction mixture containing $50 \mathrm{~mm} \mathrm{~PB}$, o-dianisidine, and $20 \mathrm{~mm} \mathrm{H}_{2} \mathrm{O}_{2}$ solution. One unit of enzyme activity was defined as the amount of MPO that caused a change in the absorbance measured at $460 \mathrm{~nm}$ for 3 min. MPO activity was expressed as $\mathrm{U} / \mathrm{g}$ tissue.

\section{Histapathological examination}

Tissues were harvested from the rats and preserved in $10 \%$ formalin. They were washed in tap water, dehydrated in an ascending series of ethanol, cleared in xylene and embedded in paraffin. Paraffin sections $5 \mu \mathrm{m}$ in thickness were cut with a microtome (Thermo Scientific Inc, MA, USA). Paraffin sections for histological observations were deparaffinized, stained with hematoxylin and eosin (H\&E), and observed with a bright field microscope (Olympus, New York Microscope Company Inc., NY, USA).

\section{Statistical analysis}

SPSS 20.0 (IBM SPSS Statistics for Windows, IBM Corporation, Armonk, NY, USA) software was used for statistical analysis. Normally distrubuted continuous variables were expressed as mean ( \pm standard deviation), and variables not normally distributed were expressed as median (range). For comparison of the three groups, the Kruskal-Wallis test was used, and the Mann-Whitney U test was used if any statistical significance was found. All tests were two-sided, and $\mathrm{p}<0.05$ was accepted as statistically significant.

\section{Results}

\section{Results of biochemical analysis}

Serum levels of ALT, AST, LDH, ALP, GGT, and total and direct bilirubin were significantly higher in both $\mathrm{I} / \mathrm{R}$ and $\mathrm{I} /$ $\mathrm{R}+\mathrm{GSE}$ groups compared to the sham group. Of them, serum ALT, AST, LDH, ALP, and GGT levels were significantly higher in I/R group than in $\mathrm{I} / \mathrm{R}+\mathrm{GSE}$ group ( $\mathrm{p}<0.01$ for all of them). However, total and direct bilirubin levels did not differ between $\mathrm{I} / \mathrm{R}$ and $\mathrm{I} /$ $\mathrm{R}+\mathrm{GSE}$ groups $(\mathrm{p}=0.148$ and $\mathrm{p}=0.108$ respectively). The detailed results are presented in Table 1 .

Tissue MDA and MPO levels were higher in both I/R and $\mathrm{I} / \mathrm{R}+\mathrm{GSE}$ groups compared to the sham group. The difference was not significant for tissue MDA level between $\mathrm{I} / \mathrm{R}+\mathrm{GSE}$ and sham groups $(\mathrm{p}=0.055)$, while there wasa significant difference both between sham vs I/R and I/R vs I/R+GSE ( $p=0.004)$. Tissue GSH levels were lower in both $\mathrm{I} / \mathrm{R}$ and $\mathrm{I} / \mathrm{R}+\mathrm{GSE}$ groups compared to the sham group. When the $\mathrm{I} / \mathrm{R}$ and $\mathrm{I} / \mathrm{R}+\mathrm{GSE}$ groups were compared, tissue MDA and MPO levels were significantly higher and tissue GSH level was significantly lower in $\mathrm{I} / \mathrm{R}$ group than in $\mathrm{I} / \mathrm{R}+\mathrm{GSE}$ group. Plasma levels of proinflammatory cytokines, TNF- $\alpha$ and IL- $1 \beta$, were significantly higher in both $\mathrm{I} / \mathrm{R}$ and $\mathrm{I} / \mathrm{R}+\mathrm{GSE}$ groups compared to the sham group ( $\mathrm{p}<0.02$ for both). Plasma levels of these cytokines were signifcantly higher in $\mathrm{I} / \mathrm{R}$ group than in $\mathrm{I} /$ $R+G S E$ group ( $p=0.004$ for TNF- $\alpha$ and $p=0.006$ for IL-1 $\beta$ ). The detailed results are summarized in Table 1. 
TABLE 1 - Labaratory Parameters and Comparison of the Groups (mean \pm SEM, n=6).

\begin{tabular}{|c|c|c|c|c|c|c|c|}
\hline & Sham & $\begin{array}{c}\text { Cholestatic } \\
\text { I/R }\end{array}$ & $\begin{array}{c}\text { Cholestatic } \\
\text { I/R+GSE }\end{array}$ & $\begin{array}{l}\text { p value } \\
\text { overall }\end{array}$ & $\begin{array}{c}\text { p value } \\
\text { sham vs. I/R }\end{array}$ & $\begin{array}{c}\text { p value } \\
\text { sham vs. I/R+- } \\
\text { GSE }\end{array}$ & $\begin{array}{c}\text { p value } \\
\text { I/R vs.I/R+- } \\
\text { GSE }\end{array}$ \\
\hline $\operatorname{ALT}(\mathrm{U} / \mathrm{L}) \dagger$ & $100.6 \pm 20.5$ & $371.7 \pm 42.7$ & $262.5 \pm 48.6$ & 0.001 & 0.000 & 0.000 & 0.002 \\
\hline $\operatorname{AST}(\mathrm{U} / \mathrm{L}) \dagger$ & $125.2 \pm 37.9$ & $1808 \pm 199.5$ & $1069 \pm 226$ & 0.001 & 0.000 & 0.000 & 0.000 \\
\hline $\mathrm{LDH}(\mathrm{U} / \mathrm{L}) \dagger$ & $652.2 \pm 104.9$ & $3919 \pm 401$ & $2295 \pm 425$ & 0.001 & 0.000 & 0.000 & 0.000 \\
\hline $\operatorname{ALP}(\mathrm{U} / \mathrm{L}) \dagger$ & $204.7 \pm 25.3$ & $714.5 \pm 53.8$ & $487 \pm 64.7$ & 0.001 & 0.000 & 0.000 & 0.000 \\
\hline GGT (U/L)† & $4.1 \pm 0.4$ & $55.4 \pm 8.2$ & $39.3 \pm 4.5$ & 0.001 & 0.000 & 0.000 & 0.002 \\
\hline DBIL $(\mathrm{mg} / \mathrm{dl}) \dagger$ & $0.4 \pm 0.01$ & $7.0 \pm 0.3$ & $6.6 \pm 0$ & 0.002 & 0.000 & 0.000 & 0.148 \\
\hline TBIL $(\mathrm{mg} / \mathrm{dl}) \dagger$ & $2.0 \pm 0.2$ & $10.9 \pm 0.8$ & $10.2 \pm 0.6$ & 0.002 & 0.000 & 0.000 & 0.108 \\
\hline TNF $\alpha(\mathrm{pg} / \mathrm{ml}) \ddagger$ & $9.9 \pm 1.5$ & $22.3 \pm 4.7$ & $13.1 \pm 2.1$ & 0.001 & 0.000 & 0.012 & 0.001 \\
\hline $\mathrm{IL}-1 \beta(\mathrm{pg} / \mathrm{ml}) \dagger$ & $208.5 \pm 26.8$ & $410.0 \pm 37.7$ & $306.2 \pm 40.1$ & 0.001 & 0.000 & 0.001 & 0.001 \\
\hline $\operatorname{MDA}(\mathrm{nmol} / \mathrm{g})^{\varsigma}$ & $28.5 \pm 5.1$ & $59.1 \pm 7.5$ & $36.7 \pm 7.4$ & 0.001 & 0.000 & 0.049 & 0.000 \\
\hline GSH $(\mathrm{nmol} / \mathrm{g})^{\Upsilon}$ & $1468 \pm 65$ & $780.7 \pm 37.8$ & $1231 \pm 99$ & 0.001 & 0.000 & 0.001 & 0.000 \\
\hline $\operatorname{MPO}(\mathrm{U} / \mathrm{g})^{\varsigma}$ & $20.6 \pm 1.3$ & $35.3 \pm 4.6$ & $29.1 \pm 2.6$ & 0.001 & 0.000 & 0.000 & 0.016 \\
\hline
\end{tabular}

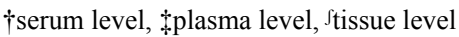

I/R: ischemia and reparfusion injury, GSE: grape seed extract, ALT: alanine transaminase, AST: aspartate transaminase, LDH: lactate dehydrogenase, ALP: alkaline phosphatase, DBIL: direct bilirubin, TBIL: total bilirubin, TNF: tumor necrosis factor, IL: interleukin, MDA: malondialdehyde, GSH: glutathione, MPO: myeloperoxidase

\section{Results of histopathological analysis}

In histopathological examination, there were some changes in liver sections, including necrosis, periportal fibrosis, and vascular and sinusoidal congestion in cholestatic I/R group (Figure 1). The histopathological appearances in cholestatic I/ $\mathrm{R}+\mathrm{GSE}$ group were similar that in the sham group except for sinusoidal diatations (Figures 2 and 3) (Table 2).

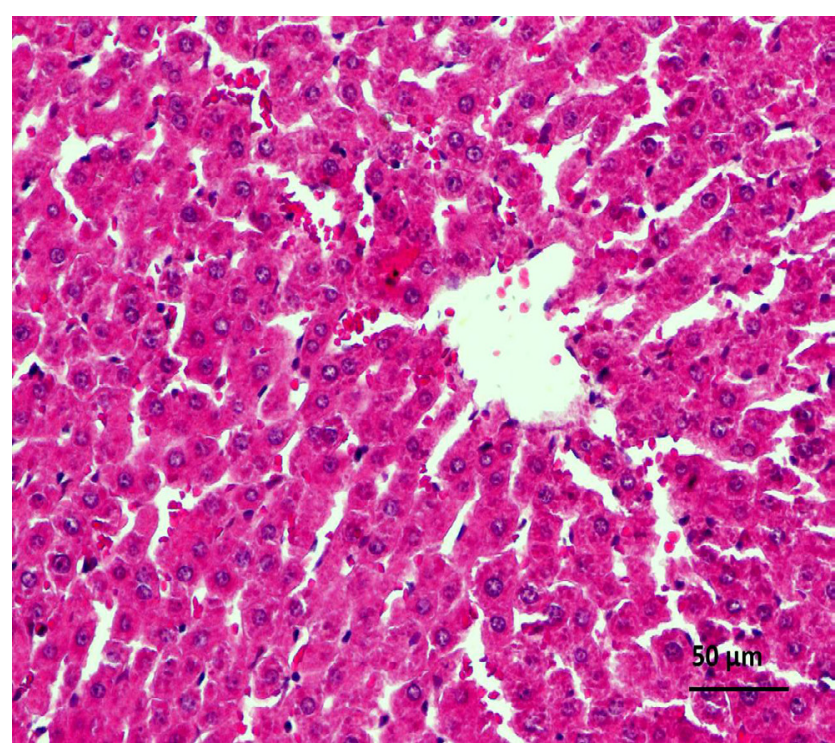

FIGURE 1 - Normal histopathological appearance of liver tissue in the sham group (H\&E, x200).

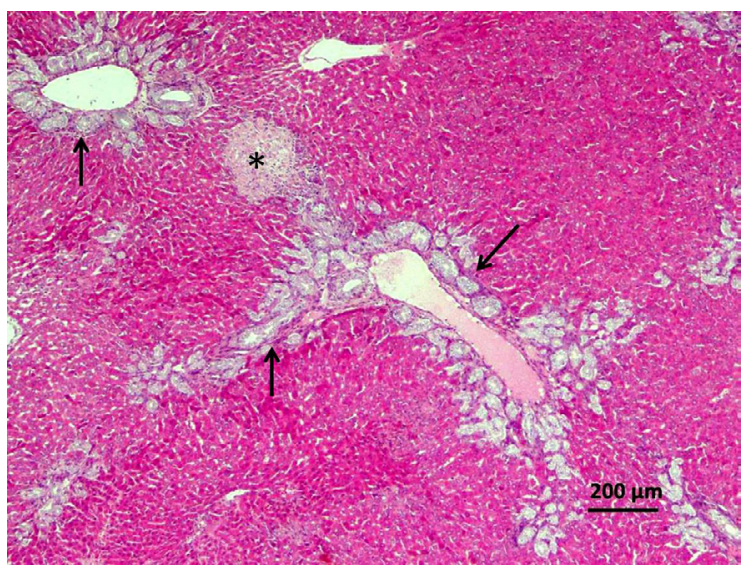

FIGURE 2 - Hepatic necrosis, increased prominency of bile duct, and fibrotic changes (arrows) in cholestatic I/R group (H\&E, x50).

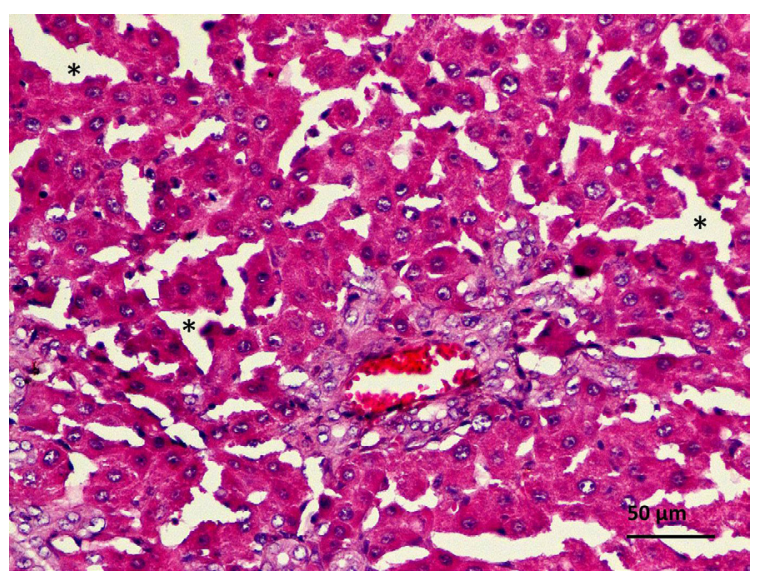

FIGURE 3 - Histopathological appearance of liver in grape-seed extract treated group. Almost normal histopathological findings, except some sinusoidal dilatations (H\&E, x200). 
TABLE 2 - The average degree of histopathologic injury was expressed as medians within each liver section of groups were shown.

\begin{tabular}{cccc}
\hline Parameters & Sham & $\begin{array}{c}\text { Cholestatic } \\
\text { I/R }\end{array}$ & $\begin{array}{c}\text { Cholestatic } \\
\text { I/R+GSE }\end{array}$ \\
\hline Vascular congestion & 0 & 1 & 0 \\
$\begin{array}{c}\text { Degeneration and } \\
\text { dilatation of the sinusoids }\end{array}$ & 0 & 2 & 1 \\
$\begin{array}{c}\text { Hydropic degeneration } \\
\text { (cellular swelling) }\end{array}$ & 0 & 1 & 0 \\
$\begin{array}{c}\text { Degeneration of } \\
\text { hepatocytes, necrosis }\end{array}$ & 0 & 1 & 0 \\
$\begin{array}{c}\text { Increase in the number of } \\
\text { activated Kupffer cells }\end{array}$ & 0 & 1 & 0 \\
Periportal fibrosis & 0 & 1 & 0 \\
Total score & 0 & 7 & 1 \\
\hline
\end{tabular}

\section{Discussion}

Ischemia, especially normothermic form, causes metabolic changes in hepatocytes especially in the mitochondria ${ }^{14}$. Failure of oxydative phosphorylation due to lack of oxygen leads to cellular ATP depletion, increase in glycolysis and formation of lactate. Additionally, the $\mathrm{Na}^{+} / \mathrm{K}^{+}$pump becomes non-functional, resulting in intracellular $\mathrm{Na}^{+}$accumulation and acceleration in function of $\mathrm{Ca}^{++} / \mathrm{Na}^{+}$pump. The overall result is an increase in intracellular $\mathrm{Ca}^{++}$level that leads to cellular damage ${ }^{14,15}$. After the reintroduction of oxygen to the ischemic tissues, toxic reactive oxygen species (ROS) are released especially from mitochondria, that are the major causes of the $\mathrm{I} / \mathrm{R}$ injury ${ }^{14}$.

Cholestasis is another cause of oxidative stress injury. Yoshidome et al. ${ }^{4}$ observed a decrease in hyaluronic acid clearence in a cholestatic liver, which is evidence of the injury of sinusoidal endothelium. Additionally, obstruction of biliary flow results in accumulation and activation of polymorphonuclear neutrophils and Kuppfer cells ${ }^{4,10}$ which trigger the oxidative stress injury ${ }^{5,6}$. The liver is more susceptible to $I / R$ injury in the presence of obstructive jaundice ${ }^{3,4}$. Although Georgiev et al. ${ }^{16}$ asserted the reverse arguments, most studies have shown a further increase in neutrophil infiltration and depending oxidative stress injury in postischemic cholestatic liver ${ }^{3,410}$. Therefore, we thought that the power of an antioxidant drug should be tested on a condition more compatible with clinical practice.

The major antioxidant component of GSE is procyanidines (or proanthocyanidins), a subtype of flavan-3-ols. Procyanidines behave as antioxidants by scavenging the ROS, chelating the transition metals, or inhibiting some enzymes ${ }^{8}$. The electronic configuration of flavan-3-ols provides easy release of electrons to ROS, by which the harmful character of the ROS is transferred to the flavan-3-ol $1^{8}$. In a relatively old study, Bagchi et $a l^{7}$ revealed that the GSE had significantly higher dose-dependent free radical scavenging capability than vitamin $\mathrm{E}$.

In a previous study, premature mortality in the first 24 hours was very high after a 45 -minute ischemic period in the cholestatic $\mathrm{I} / \mathrm{R}$ injury model ${ }^{3}$. Therefore we have preffered thirty minutes of ischemia time for this animal model.

Reduced form of glutathion (GSH) underwent oxidation with the enzymatic effect of gluthatione peroxidase to eliminate the ROS and release oxidized glutathion (GSSG) in hepatocytes ${ }^{14}$. Accordingly, GSH has an important mission against oxidative stress injury ${ }^{14}$. Hepatic GSH production decreases during normothermic ischemia, and discharge of ROS during reperfusion phase causes rapid consumption of $\mathrm{GSH}^{19,20}$. These two mechanisms cause decreases in both intracellular and extracellular GSH levels, which causes oxidation and degration of important structures in the cell such as proteins, lipids, or double strand structure of DNA ${ }^{20}$. Therefore, the tissue GSH level has been accepted as a marker for oxidative stress injury. Less tissue GSH level means more oxidative stress injury ${ }^{21}$. In our study, GSE treatment provides attenuation of oxidative stress injury in a cholestatic I/R injury model. The decrease in tissue GSH level is significantly less in I/ $\mathrm{R}+\mathrm{GSE}$ group than in $\mathrm{I} / \mathrm{R}$ group in the setting of cholestasis $(\mathrm{p}<$ $0.0001)$.

Lipid peroxidation is another important part of oxidative stress injury. Lipids in cellular membranes underwent lipid peroxidation, leading cellular damage. The end product of this reaction is $\mathrm{MDA}^{17}$. In the current study, I/R injury caused a huge amount of MDA accumulation in the liver. The mean value of liver MDA level was more than 2-fold that of normal liver tissue. In the previous studies about $\mathrm{I} / \mathrm{R}$ injury, 1.5 - to 4 -fold of basal level of MDA was obtained ${ }^{9,22-24}$. Therefore, it is certain that the tissue MDA level can reflect exactly the severity of the oxidative stress injury. According to our results, GSE treatment attenuated the lipid peroxidation effectively; thus, liver MDA level was very close to the basal level in normal liver (sham vs. cholestatic I/ $\mathrm{R}+\mathrm{GSE} ; \mathrm{p}=0.049$ ).

Kupffer cells and polymorphonuclear neutrophils are the other participants in $I / R$ injury reactions, and they are the main sources of the ROS during I/R injury ${ }^{6}$. Therefore, the oxidative activity should be proportional with the activity and number of these cells. MPO level in a tissue is directly proportional with the number of activated neutrophils and Kupffer cells that was previously used to evaluate the $\mathrm{I} / \mathrm{R}$ injury in both liver and 
small intestine ${ }^{18,25}$. Furthermore, activated Kupffer cells release cytokines, especially TNF $\alpha$ and IL-1 $\beta$, in addition to $\operatorname{ROS}^{14}$. Increases in polimorphonuclear neutrophils and activity of Kupffer cells, reflected by tissue MPO, plasma TNF $\alpha$, and IL-1 $\beta$ levels, are indicators of both oxidative stress and inflammatory reaction $^{5,8,14}$. In the current study, cholestatic I/R injury caused a significant increase in the levels of tissue MPO, and plasma TNF $\alpha$ and IL-1 $\beta$. With the GSE treatment, all were significantly lowered in comparison to the cholestatic I/R injury group $(p=0.016$ for MPO; $\mathrm{p}<0.001$ for TNF $\alpha$ and IL-1 $\beta$ ).

According to the results of the current study, although GSE treatment significantly decreased the oxidative stress in cholestatic I/R model, the reduction was not enough to reach the basal level of the normal liver. Thus, there were statistically significant differences for all oxidative stress parameters between the cholestatic $\mathrm{I} / \mathrm{R}+\mathrm{GSE}$ group and the sham group. In contrast, Sehirli et al. ${ }^{9}$ reported that the liver GSH, MPO and MDA levels reversed to the levels in the control group with oral GSE treatment in I/R injury model without cholestasis. Likewise, Dulundu et al. ${ }^{10}$ revealed that GSE treatment returned the liver tissue GSH, MPO, and MDA levels to almost-normal basal level in the cholestatic model without I/R. Relatively less success in our study may be related to differences in experimental models; hence, in our study, the combination of cholestatsis and I/R might deepen the oxidative stress injury. In another study, significant antioxidant effect of intraperitoneal grape seed proanthocyanidin administiration was demonstrated, but the level of oxidative stress parameters, including GSH, MDA, TNF $\alpha$ and IL-1 $\beta$, did not reach the basal level of normal liver even with ischemic postconditioning ${ }^{26}$. According to these data, although GSE treatment decreases the oxidative stress injury after reperfusion, it seems to be infufficient to reach the normal hepatic status. However, the present effect may be reasonable for clinical improvement.

In this study, cholestatic I/R damaged the hepatocytes, sinusoidal endothelial cells, and biliary ductal epithelium. The presence of these damages was proven by a significant increase in AST, ALT, ALP, and GGT in cholestatic I/R group. Additionally histopathological examination revealed a hepatic necrosis, endothelial swelling and fibrosis. GSE treatment provides significant improvement in the levels of these parameters, although the level of bilirubin did not improve. The succcess of GSE tretment was seen in the histopthological examination. Hence, almost normal liver tissue appearance except for some sinusoidal dilatations was seen in histopathological examination of liver tissue of the cholestatic I/R+GSE group.

\section{Conclusions}

Reperfusion of the liver after a period of ischemia in a cholestatic model causes considerable increase in proinflammatory cytokines in bloodstream and oxidative stress in liver tissue. The overall results are hepatocellular and sinusoidal endothelial damage. Oral GSE treatment can improve the liver functions and attenuate the inflammation and oxidative stress in the cholestatic $\mathrm{I} / \mathrm{R}$ injury. These experimental findings demonstrated that GSE appears to be an effective agent against hepatic $I / R$ injury in a cholestatic liver.

\section{References}

1. Jaeschke H, Woolbright BL. Current strategies to minimize hepatic ischemia-reperfusion injury by targeting reactive oxygen species. Transplant Rev (Orlando). 2012 Apr;26(2):103-14. doi: 10.1016/j. trre.2011.10.006.

2. Yamanaka K, Houben P, Bruns H, Schultze D, Hatano E, Schemmer P. A systematic review of pharmacological treatment options used to reduce ischemia reperfusion injury in rat liver transplantation. PLoS One. 2015 Apr 28;10(4):e0122214. doi: 10.1371/journal. pone.0122214.

3. Kloek JJ, Marsman HA, van Vliet AK, Gouma DJ, van Gulik TM. Biliary drainage attenuates postischemic reperfusion injury in the cholestatic rat liver. Surgery. 2008 Jul;144(1):22-31. doi: 10.1016/j. surg.2008.03.030.

4. Yoshidome H, Miyazaki M, Shimizu H, Ito H, Nakagawa K, Ambiru S, Nakajima N, Edwards MJ, Lentsch AB. Obstructive jaundice impairs hepatic sinusoidal endothelial cell function and renders liver susceptible to hepatic ischemia/reperfusion. J Hepatol. 2000 Jul;33(1):59-67. PMID: 10905587.

5. Jaeschke H, Farhood A, Smith CW. Neutrophils contribute to ischemia/reperfusion injury in rat liver in vivo. FASEB J. 1990 Dec;4(15):3355-9. PMID: 2253850.

6. Datta G, Fuller BJ, Davidson BR. Molecular mechanisms of liver ischemia reperfusion injury: insights from transgenic knockout models. World J Gastroenterol. 2013 Mar 21;19(11):1683-98. doi: 10.3748/wjg.v19.i11.1683.

7. Bagchi D, Garg A, Krohn RL, Bagchi M, Tran MX, Stohs SJ. Oxygen free radical scavenging abilities of vitamins $\mathrm{C}$ and $\mathrm{E}$, and a grape seed proanthocyanidin extract in vitro. Res Commun Mol Pathol Pharmacol. 1997 Feb;95(2):179-89. PMID: 9090754.

8. Aron PM, Kennedy JA. Flavan-3-ols: nature, occurrence and biological activity. Mol Nutr Food Res. 2008 Jan;52(1):79-104. Review. PMID: 18081206.

9. Sehirli O, Ozel Y, Dulundu E, Topaloglu U, Ercan F, Sener G. Grape seed extract treatment reduces hepatic ischemia-reperfusion injury in rats. Phytother Res. 2008 Jan;22(1):43-8. doi: 10.1002/ptr.2256.

10. Dulundu E, Ozel Y, Topaloglu U, Toklu H, Ercan F, Gedik N, Sener G. Grape seed extract reduces oxidative stress and fibrosis in experimental biliary obstruction. J Gastroenterol Hepatol. 2007 Jun;22(6):885-92. PMID:17565645.

11. Buege JA, Aust SD. Microsomal lipid peroxidation. Methods Enzymol. 1978;52:302-10. PMID: 672633.

12. Beutler E. Glutathione in red blood cell metabolism. A manual of biochemical methods. New York: Grune \&Stratton; 1975.

13. Hillegass LM, Griswold DE, Brickson B, Albrightson-Winslow C. Assessment of myeloperoxidase activity in whole rat kidney. J Pharmacol Methods. 1990 Dec;24(4):285-95. PMID: 1963456. 
14. Peralta C, Jiménez-Castro MB, Gracia-Sancho J. Hepatic ischemia and reperfusion injury: effects on the liver sinusoidal milieu. J Hepatol. 2013 Nov;59(5):1094-106. doi: 10.1016/j. jhep.2013.06.017.

15. Gasbarrini A, Borle AB, Farghali H, Bender C, Francavilla A, van Thiel D. Effect of anoxia on intracellular ATP, Na+i, Ca2+i, $\mathrm{Mg} 2+\mathrm{i}$, and cytotoxicity in rat hepatocytes. J Biol Chem. 1992 Apr 5;267(10):6654-63. Erratum in: J Biol Chem 1992 Jun 25;267(18):13114. PMID: 1637381.

16. Georgiev P, Navarini AA, Eloranta JJ, Lang KS, Kullak-Ublick GA, Nocito A, Dahm F, Jochum W, Graf R, Clavien PA. Cholestasis protects the liver from ischaemic injury and post-ischaemic inflammation in the mouse. Gut. 2007 Jan;56(1):121-8. PMID: 16763052

17. Heim KE, Tagliaferro AR, Bobilya DJ. Flavonoid antioxidants: chemistry, metabolism and structure-activity relationships. J Nutr Biochem. 2002 Oct;13(10):572-84. PMID: 12550068.

18. Yildiz F, Coban S, Terzi A, Aksoy N, Bitiren M. Protective effect of micronized purified flavonoid fraction on ischemia/reperfusion injury of rat liver. Transplant Proc. 2015 Jun;47(5):1507-10. doi:10.1016/j.transproceed.2015.04.062.

19. Koeppel TA, Lehmann TG, Thies JC, Gehrcke R, Gebhard MM, Herfarth C, Otto G, Post S. Impact of N-acetylcysteine on the hepatic microcirculation after orthotopic liver transplantation. Transplantation. 1996 May 15;61(9):1397-402. PMID: 8629304.

20. Stein HJ, Oosthuizen MM, Hinder RA, Lamprechts H. Oxygen free radicals and glutathione in hepatic ischemia/reperfusion injury. $\mathrm{J}$ Surg Res. 1991 Apr;50(4):398-402. PMID: 2020191.

21. Paracha UZ, Fatima K, Alqahtani M, Chaudhary A, Abuzenadah A, Damanhouri G, Qadri I. Oxidative stress and hepatitis C virus. Virol J. 2013 Aug 7;10:251. doi:10.1186/1743-422X-10-251.

22. Liu PG, He SQ, Zhang YH, Wu J. Protective effects of apocynin and allopurinol on ischemia/reperfusion-induced liver injury in mice. World J Gastroenterol. 2008 May 14;14(18):2832-7. PMID: 18473406

23. Abdel-Gaber SA, Ibrahim MA, Amin EF, Ibrahim SA, Mohammed RK, Abdelrahman M. Effect of selective versus non-selective cyclooxygenase inhibitors on ischemia-reperfusion-induced hepatic injury in rats. Life Sci. 2015 Aug 1;134:42-8. doi: 10.1016/j. lfs.2015.04.025
24. Kocak FE, Kucuk A, Ozyigit F, Tosun M, Kocak C, Kocak A, Ekici MF, Yaylak F, Genc O. Protective effects of simvastatin administered in the experimental hepatic ischemia-reperfusion injury rat model. $\mathrm{J}$ Surg Res. 2015 Dec;199(2):393-401. doi: 10.1016/j.jss.2015.06.009.

25. Ji YY, Wang ZD, Wang SF, Wang BT, Yang ZA, Zhou XR, Lei NN, Yue WN. Ischemic preconditioning ameliorates intestinal injury induced by ischemia-reperfusion in rats. World $\mathrm{J}$ Gastroenterol. 2015 Jul 14;21(26):8081-8. doi:10.3748/wjg.v21.i26.8081.

26. Song X, Xu H, Feng Y, Li X, Lin M, Cao L. Protective effect of grape seed proanthocyanidins against liver ischemic reperfusion injury: particularly in diet-induced obese mice. Int $\mathrm{J}$ Biol Sci. 2012;8(10):1345-62. doi:10.7150/ijbs.4699.

\section{Correspondence:}

Tuğrul Çakır

Antalya Taining and Research Hospital Transplantation

General Surgery Department

070100, Antalya, TurkeyPhone: +902422494400-3381

Gsm: +90 5057323505

Fax: +90242 2494462

tugrul-cakir@hotmail.com

Received: Nov 16, 2015

Review: Jan 18, 2016

Accepted: Feb 19, 2016

Conflict of interest: none

Finacial source: Educational and Research Planning Funding of Antalya Training and Research Hospital.

${ }^{1}$ Research performed at Research Laboratory, Akdeniz University of Medicine, Antalya, Turkey. 